Military Technical College Kobry El-Kobbah, Cairo, Egypt

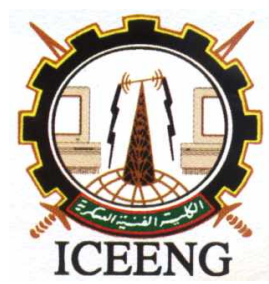

\author{
$6^{\text {th }}$ International Conference \\ on Electrical Engineering \\ ICEENG 2008
}

\title{
The phenomena of leaky modes exicitation in hybrid metal-dielectric structure
}

\author{
By \\ D.V. Mayboroda* \\ S. A. Pogarsky*
}

\section{Abstract:}

The hybrid metal dielectric structure which is combined a microstrip line section and bounded periodical sequence of slot discontinuities are investigated. The boundary problem for a single discontinuity is solved with the help of spectral-domain approach. For the definition of the parameters of bounded sequences of discontinuities the operator technique is used. If one introduces the slot discontinuity into the $\mathrm{T}$ - wave propagation region one can observed the phenomena of leaky modes excitation around the cut-off frequencies of microstrip line is established, They may be classified as surface-wave leaky modes and space-wave leaky modes. The excitation efficiency dependence by the couple value of the discontinuity and basic waveguide is investigated.

\section{Keywords:}

microstip line, longitudinal slot, eigenwave 


\section{Introduction:}

The basic question in the investigations of the characteristics of slot structures is the question about spectrum of eigenwaves and influence of any design features on the spectrum structure of the propagating waves. In the most of well-known investigations, it was presupposed that the planar structure are endless in both direction [1-3]. At the same time the real components and devices have a finite linear dimension and moreover, in the majority cases they have shielded either partially or fully. The main goal of our research is the investigation of constrictive elements influence on the characteristics of radiating system based on metal-dielectric structure (MDS).

\section{Analysis:}

Let us examine the influence of constrictive element on eigenwave spectrum of basic structure which is represented the partially shielded microstrip line (Fig.1).

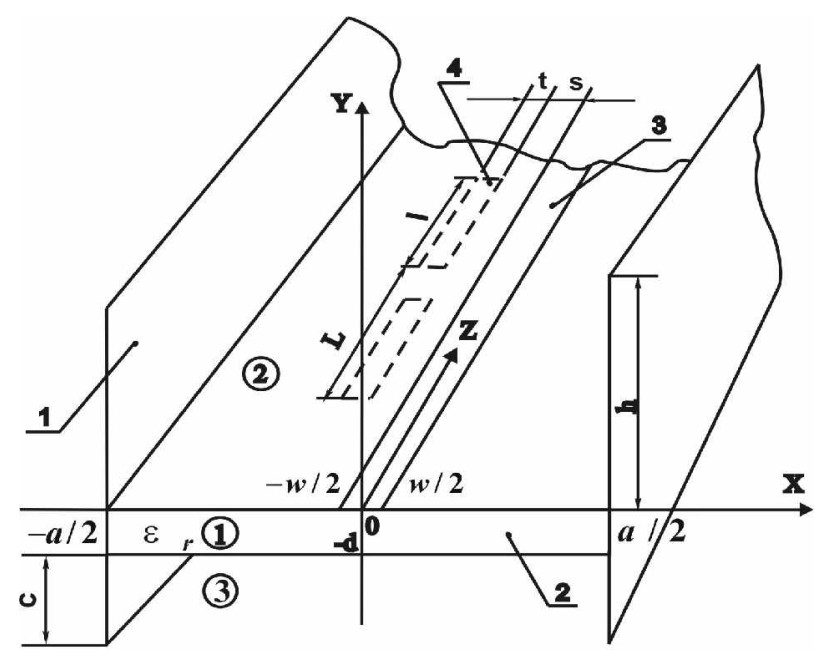

Figure (1): The basic structure

We'll find the decision with the following assumptions: in regions $-\mathrm{d}<\mathrm{Y}<0$, $-\mathrm{a} / 2<\mathrm{X}<\mathrm{a} / 2$ dielectric is homogeneous and isotropic with $\varepsilon_{\mathrm{r}}=\varepsilon_{2}, \mu_{\mathrm{r}}=\mu_{2}$ in all space $\varepsilon_{\mathrm{r}}=\varepsilon_{1}, \mu_{\mathrm{r}}=\mu_{1}$ conductivity of metal conductors is infinity; the thickness of microstrip conductor is infinitesimilar. The electromagnetic fields in the structure may be determined with the help of magnetic and electrical Hertz potentials: 


$$
\begin{aligned}
& \dot{\mathrm{E}}^{(\mathrm{s})}=\operatorname{graddiv} \Pi_{(\mathrm{s})}^{\mathrm{e}}-\mathrm{i} \omega \mu_{\mathrm{a}} \operatorname{rot} \Pi_{(\mathrm{s})}^{\mathrm{m}}+\mathrm{k}^{2} \varepsilon_{\mathrm{a}}^{(\mathrm{s})} \mu_{(\mathrm{a})}^{(\mathrm{s})} \dot{\Pi}_{(\mathrm{s})}^{\mathrm{e}}, \\
& \dot{\mathrm{H}}^{(\mathrm{s})}=\mathrm{i} \omega \varepsilon_{\mathrm{a}} \operatorname{rot} \Pi_{(\mathrm{s})}^{\mathrm{e}}+\operatorname{graddiv} \Pi_{(\mathrm{s})}^{\mathrm{m}}+\mathrm{k}^{2} \varepsilon_{\mathrm{a}}^{(\mathrm{s})} \mu_{(\mathrm{a})}^{(\mathrm{s})} \dot{\Pi}_{(\mathrm{s})}^{\mathrm{m}},
\end{aligned}
$$

where $\mathrm{s}=1,2$ - are the number of the partial regions, $\dot{\Pi}_{(\mathrm{s})}^{\mathrm{e}}(\mathrm{x}, \mathrm{y}, \mathrm{z}), \dot{\Pi}_{(\mathrm{s})}^{\mathrm{m}}(\mathrm{x}, \mathrm{y}, \mathrm{z})-$ the Hertz potentials of TM and TE modes in partial regions. The Hertz vectors satisfying the Helmhotlz equations and with the longitudinal coordinates dependence in the form as $e^{-i \gamma z}$ may be represented as:

$$
\begin{aligned}
& \Pi_{\mathrm{y}(1)}^{\mathrm{e}}=\sum_{\mathrm{m}=0}^{\infty}\left\{-\mathrm{A}_{\mathrm{m}} \frac{\cos \left[\mathrm{k}_{\mathrm{y}(1) \mathrm{m}}(\mathrm{y}+\mathrm{d})\right]}{\sin \left[\mathrm{k}_{\mathrm{y}(1) \mathrm{m}}(\mathrm{d} / 2)\right]}+\mathrm{B}_{\mathrm{m}} \frac{\sin \left[\mathrm{k}_{\mathrm{y}(1) \mathrm{m}}(\mathrm{y}+\mathrm{d})\right]}{\sin \left[\mathrm{k}_{\mathrm{y}(1) \mathrm{m}}(\mathrm{d} / 2)\right]}\right\} \cos \left[\frac{(2 \mathrm{~m}+1) \pi}{\mathrm{a}} \mathrm{x}\right] \mathrm{e}^{-\mathrm{i} \gamma z} \\
& \Pi_{\mathrm{y}(1)}^{\mathrm{m}}=\sum_{\mathrm{m}=0}^{\infty}\left\{\mathrm{C}_{\mathrm{m}} \frac{\cos \left[\mathrm{k}_{\mathrm{y}(1) \mathrm{m}}(\mathrm{y}+\mathrm{d})\right]}{\cos \left[\mathrm{k}_{\mathrm{y}(1) \mathrm{m}}(\mathrm{d} / 2)\right]}+\mathrm{D}_{\mathrm{m}} \frac{\sin \left[\mathrm{k}_{\mathrm{y}(1) \mathrm{m}}(\mathrm{y}+\mathrm{d})\right]}{\cos \left[\mathrm{k}_{\mathrm{y}(1)}(\mathrm{d} / 2)\right]}\right\} \sin \left[\frac{(2 \mathrm{~m}+1) \pi}{\mathrm{a}} \mathrm{x}\right] \mathrm{e}^{-\mathrm{i} \gamma \mathrm{z}}, \\
& \left\{\begin{array}{l}
\Pi_{\mathrm{y}(2)}^{\mathrm{e}}=\sum_{\mathrm{m}=0}^{\infty} \mathrm{E}_{\mathrm{m}} \mathrm{e}^{-\mathrm{i} \mathrm{k}_{\mathrm{y}(2) \mathrm{m}} \mathrm{y}} \cos \left[\frac{(2 \mathrm{~m}+1) \pi}{\mathrm{a}} \mathrm{x}\right] \mathrm{e}^{-\mathrm{i} z \mathrm{z} z} ; \\
\Pi_{\mathrm{y}(2)}^{\mathrm{m}}=\sum_{\mathrm{m}=0}^{\infty} \mathrm{F}_{\mathrm{m}} \mathrm{e}^{-\mathrm{i} \mathrm{k}_{\mathrm{y}(2) \mathrm{m}} \mathrm{y}} \sin \left[\frac{(2 \mathrm{~m}+1) \pi}{\mathrm{a}} \mathrm{x}\right] \mathrm{e}^{-\mathrm{i} z \mathrm{z}},
\end{array}\right.
\end{aligned}
$$

where $\mathrm{k}_{\mathrm{y}(\mathrm{s}) \mathrm{m}}^{2}=\varepsilon_{\mathrm{r}(\mathrm{s})} \mathrm{k}_{0}^{2}-\left[\frac{(2 \mathrm{~m}+1) \pi}{\mathrm{a}}\right]^{2}-\gamma^{2} ; \mathrm{k}_{0}=\frac{\omega}{\mathrm{c}}$ - wave number; $\gamma$-is the propagation constant. The components of the fields may be received with the help of the equations (1).The satisfaction of the boundary conditions leads to the system of function equations which may be transform in to the system of linear algebraic equations by the moment's method. This procedure may be realized by the expansion of the surface current functions in the series of Chebyshev polynomials of the $1^{\text {st }}$ and $2^{\text {nd }}$ kinds:

$$
\begin{aligned}
& I_{z}=\left[1-\left(\frac{x^{\prime}}{w / 2}\right)\right]^{-1 / 2} \sum_{n=0}^{N} a_{n} T_{2 n}\left(\frac{x^{\prime}}{w / 2}\right) \\
& I_{x}=\sqrt{1-\left(\frac{x^{\prime}}{w / 2}\right)^{2}} \sum_{n=0}^{N} b_{n} U_{2 n+1}\left(\frac{x^{\prime}}{w / 2}\right) .
\end{aligned}
$$


The introducing in to propagation region of electromagnetic wave a discontinuity such as longitudinal slot (or sequences of slots) leads to the fundamentally changes of electrodynamical wave propagation regime: in the propagation region the quasi $-\mathrm{T}$ wave will exist as far as infinitely long, and at the same time as surface and space leaky waves may be exited. The main assumption of the boundary problem is that the slot is narrow, i.e. $l>>t, \lambda>>t$. This assumption allows to confirm that the electric field is transverse the slot. Let's assume that the screen of the MDS is infinitely thick and infinitely conductive. The Hertz potential in the $3^{\text {rd }}$ partial region may be written in the form:

$$
\left\{\begin{array}{l}
\Pi_{y(3)}^{e}=\sum_{m=0}^{\infty} G_{m} e^{i k_{y(3) m}(y+d)} \cos \left[\frac{(2 m+1) \pi}{a} x\right] e^{-i \gamma z} \\
\Pi_{y(3)}^{m}=\sum_{m=0}^{\infty} K_{m} e^{i k_{y(3)}(y+d)} \sin \left[\frac{(2 m+1) \pi}{a} x\right] e^{i \gamma z} .
\end{array}\right.
$$

The procedure of the nonlinear coupled system of functional equations receiving have no any principle features in comparing with the procedure (3-7) the main difference is consisting in formulation the boundary conditions relatively magnetic currents which is exiting the slot.

$$
\stackrel{\dot{M}}{\mathrm{M}}=\mathrm{M}_{\mathrm{x}} \mathrm{r}_{0}+\dot{\mathrm{M}}_{\mathrm{z}}^{\mathrm{z}} \mathrm{z}_{0}=\left[\stackrel{\mathrm{e}}{\mathrm{E}}, \mathrm{r}_{0}\right]
$$

\section{The computational modeling results:}

On the basis of created model the complex simulation of parameters was made. The two structures with coaxial and with the shift of microstrip and slot axis's on $3 \mathrm{~mm}$ were chosen as basic structures. It was established that a single slot discontinuity has weakly influence on quasi-T wave propagation regime. In Fig. 3, 4 the simulation characteristics of reflection $\left|S_{11}\right|$ and passing coefficients $\left|S_{12}\right|$ in 2-12 GHz frequency band are represented. 

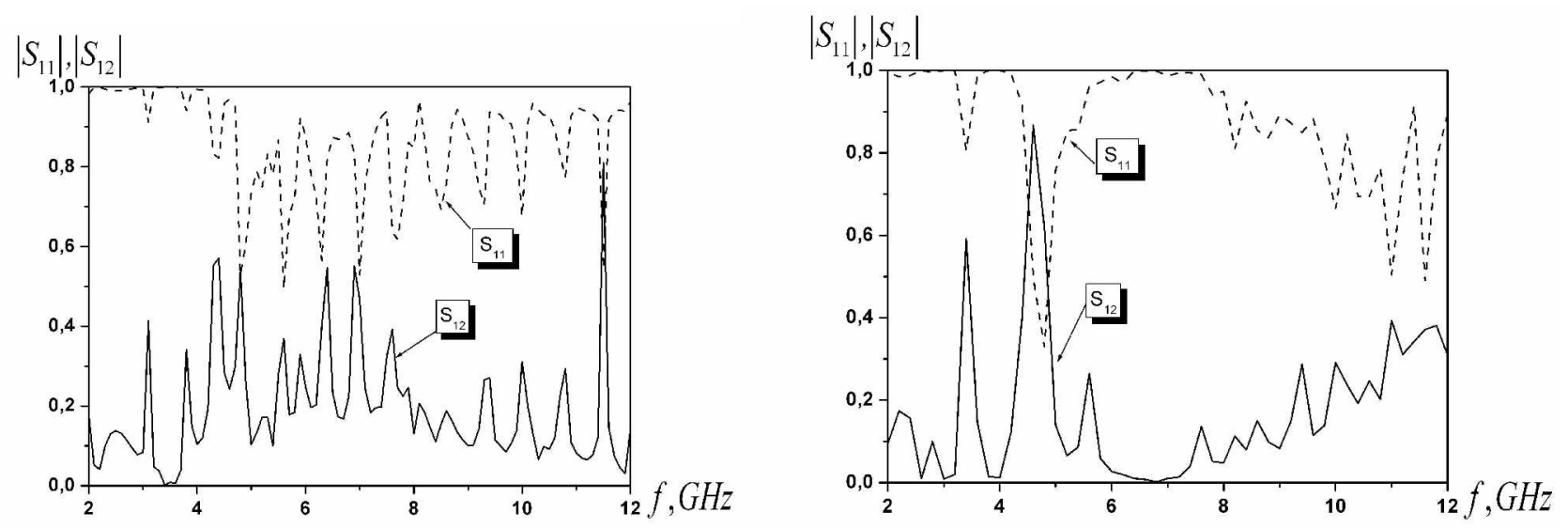

Figure (3,4): The $|\mathrm{S}|$ parameter characteristics

The analysis of the dependences represented in Fig. 3 shows the significant character: if the shift of axis's is absent, it is observed practically complete reflection in low frequency band and it is observed an oscillation of $\left|\mathrm{S}_{11}\right|$ characteristic with high medium level in high frequency band. The shift appearance $(\mathrm{s}=3 \mathrm{~mm})$ results in essential changes of wave propagation regime (Fig. 4). In characteristics represented in Fig. 4 there are well-defined peculiarities in $\left|S_{11}\right|$ characteristic around three frequencies: $\mathrm{f}_{1}=3.4 \mathrm{GHz}, \mathrm{f}_{2}=4.75 \mathrm{GHz}$ and $\mathrm{f}_{3}=7.85 \mathrm{GHz}$. The minimum value observed on $\mathrm{f}_{2}=4.75 \mathrm{GHz}$. On this frequency the ratio $1 / \lambda_{0}$ is approximately 0.5 for slot length $1=30 \mathrm{~mm}$. Near frequency $\mathrm{f}_{3}=7.85 \mathrm{GHz}$ there is local poor frequency response. This frequency coincides with cut-off frequency one of the high mode. It is possible to forecast the effective radiation from slot around these frequencies.

\section{The experimental measurements:}

The series of experimental measurements were carried out. In Fig. 5 and Fig. 6 the pattern characteristics measured on $\mathrm{f}=3.4 \mathrm{GHz}$ and $\mathrm{f}=4.75 \mathrm{GHz}$ are represented. One can find the radiation from both sides of structure. If the resonant condition is meeting $\left(1 / \lambda_{0} \approx 0.5\right)$, the maximum radiation observes from the side with slot radiator. In this situation the pattern characteristic has practically single-lobe beam (the level of side lobes are less than 0.15 ). The width of the beam is approximately 12 degrees by the 0.707 level. However the main lobe has a shift relatively normal about 60 degrees, it is caused by linear phase distribution on the radiator. 

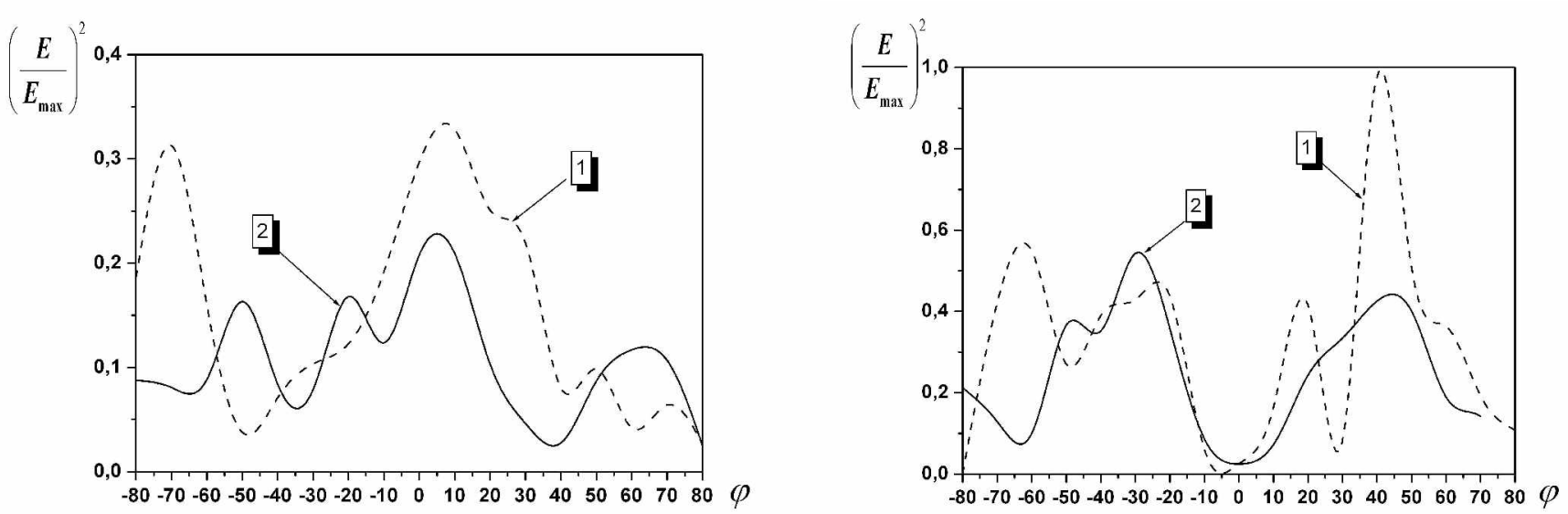

Figure (5,6): The pattern characteristics

If the ratio $1 / \lambda_{0}$ is equal 0.34 (Fig. 5) the pattern characteristics are multi-lobe. The maximum of radiation observes from the side with microstrip line. The main beam has a shift from normal too. The width of the beam increased till 35 degrees. The measurements of electric field intensity in near zone by probe technique allow to confirm the theoretical prediction [4] about transformation effect of high order waves into two types of leakage waves: surface and space leakage waves. In Fig. 7 the contour lines of electric field measured on frequency $f=5 \mathrm{GHz}$ are represented. This frequency was chosen near the cut-off frequency of one of the high mode (deviation from cut-off frequency is equally $5 \%$. The measurements on this frequency directly are impossible as a result of unstable wave regime. In the Fig.7 the regions with the similar intensity of electrical field are indicates by rectangular. The presences of that kind of regions allow estimating a length of the exciting waves. In the one case the wave length may be estimate by the value of $\lambda_{\mathrm{g} 1} \approx 7.98 \mathrm{~cm}$ in the second case $\lambda_{\mathrm{g} 2} \approx 4 \mathrm{~cm}$ with value of $\lambda_{0} \approx 6 \mathrm{~cm}$. The defining values allow to conclude that in structure with a slot discontinuity besides the basic quasi $-T$ wave two types of waves with delay coefficients $\xi=1.3$-slow surface wave and another one with $\xi=0.7$-fast space wave are excited. 


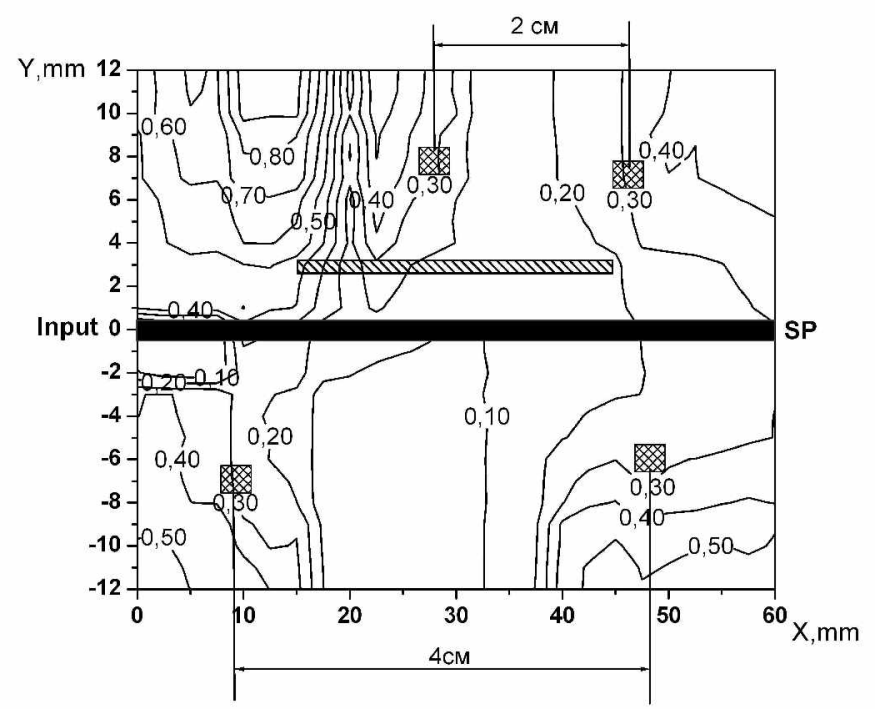

Figure (7): The counter lines of an electrical field

\section{Conclusions:}

In that way, the carried out investigations show the possibility of the radiating model designing with high level parameters and special pattern characteristics. It is actually to take into account the dependencies of characteristics by the peculiarities of construction such as laterally shielding.

\section{References:}

[1]. G. Kompa, R. Mehran, Planar waveguide model for calculating microstrip components, Electron. Letters, Vol. 11, P.459 -460, November 1975.

[2] T.Y. Lo, D. Solomon, W.F. Richards, Theory and experiment on microstrip antennas, IEEE Transactions on Antennas and Propagation, Vol. 27, No 3, PP. 137-145, March 1979.

[3] L. Giauffret, J-M. Laheurte, A. Papernik, Study of various shapes of the coupling slot in CPW-fed microstrip antennas, IEEE Transactions on Antennas and Propagation, Vol. 45, No.4, P. 642-647, April 1997.

[4] F. Mesa, D. Jackson, M. Freire, Evolution of leaky modes on printed - circuit lines, IEEE Transactions on Microwave Theory and Techniques, Vol. 50, No 1, P. 94 - 104, January 2002. 